\title{
Protective Effect of Ketamine against Acetic Acid-Induced Ulcerative Colitis in Rats
}

\author{
Esraa Elsayed Ashry, Rasha Bakheet Abdellatief, Abeer Elrefaiy Mohamed, \\ Hassan Ibrahim Kotb \\ Faculty of Medicine, Assiut University, Assiut, Egypt \\ Email: esraaashry@yahoo.co.uk, r bakheet@yahoo.com, Abeer refaiy@yahoo.com, kotbhi@yahoo.com
}

Received 8 December 2015; accepted 10 January 2016; published 13 January 2016

Copyright (C) 2016 by authors and Scientific Research Publishing Inc.

This work is licensed under the Creative Commons Attribution International License (CC BY).

http://creativecommons.org/licenses/by/4.0/

(c) (i) Open Access

\section{Abstract}

Objective: Inflammatory bowel diseases (IBD), including Crohn's disease and ulcerative colitis (UC), are chronic and recurrent disorders of the gastrointestinal tract with unknown etiology. Considering the adverse effects and incomplete efficacy of currently administered drugs, it is crucial to explore new drugs with more desirable therapeutic profiles. As non-competitive N-methylD-aspartate (NMDA) receptor antagonists have shown analgesic and anti-inflammatory properties in vitro and in vivo, this study aims to investigate the role of ketamine, a noncompetitive NMDA receptor antagonist, in acetic acid-induced rat colitis. Methods: Ketamine (10, $50 \mathrm{mg} / \mathrm{kg})$, and dexamethasone $(1 \mathrm{mg} / \mathrm{kg}$ ) were given intraperitoneally $30 \mathrm{~min}$ before induction of colitis which was done by instillation of $2 \mathrm{~mL}$ of $4 \%$ acetic acid (vol/vol). At the $4^{\text {th }}$ day of colitis induction, animals were sacrificed and distal colons were assessed macroscopically and microscopically. Furthermore, the mucosal contents of lipid peroxidation (LPO), reduced glutathione (GSH), nitric oxide (NO) and tumor necrosis factor- $\alpha$ (TNF- $\alpha$ ) were assessed. Results: Ketamine (50 mg/ kg) and dexamethasone significantly $(p<0.05)$ improved macroscopic and histologic scores, diminished colonic levels of MDA, NO and TNF- $\alpha$ and elevated GSH levels. Conclusion: Our data suggest that ketamine has valuable protective effects in acetic acid colitis and it may be a new therapy target in ulcerative colitis patients, possibly by regulating antioxidants and inflammatory mediators.

\section{Keywords}

Ketamine, Ulcerative Colitis, Rats

\section{Introduction}

Ulcerative colitis is a chronically recurrent inflammatory bowel disease. Although its etiology remains essentially unknown, yet studies suggest that genetic susceptibility, altered immune response and environmental factors are involved in both initiation and progression of colitis. Despite the great deal of attention for this disease

How to cite this paper: Ashry, E.E., Abdellatief, R.B., Mohamed, A.E. and Kotb, H.I. (2016) Protective Effect of Ketamine against Acetic Acid-Induced Ulcerative Colitis in Rats. Pharmacology \& Pharmacy, 7, 9-18. 
during the past years, its pharmacological treatment is still unsatisfactory [1] [2].

The acetic acid-induced ulcerative colitis is a widely used animal model of ulcerative colitis [3]-[5]. This experimental model resembles ulcerative colitis in histology, eicosanoid production and response to sulfasalazine [6].

Management of inflammatory bowel diseases (IBD) is based on aminosalicylates, glucocorticoids, immunomodulators and more recently monoclonal antibodies. Nevertheless, the high incidences of adverse effects together with the failure to be generally efficacious make it indispensable to explore new candidates with more desirable therapeutic profiles [7].

Ketamine, a noncompetitive N-methyl-D-aspartate (NMDA) receptor antagonist, is commonly used as an intravenous or intramuscular anesthetic. Several investigators show that administration of ketamine has protective effects against polymicrobial sepsis in rats. Ketamine probably inhibits NF- $\kappa$ B activation and attenuates the proinflammatory cytokine response. It was reported that ketamine has inhibitory effects on lipopolysaccharide (LPS)-induced TNF- $\alpha$ production in endotoxin-induced shock in rats [8] [9]. Others have documented that ketamine could suppress proinflammatory cytokines production in human whole blood in vitro [10] [11].

In the present study, we have evaluated the protective effects of ketamine, a noncompetitive N-methyl-D-aspartate (NMDA) receptor antagonist, against acetic acid-induced colitis in rats.

\section{Materials and Methods}

\subsection{Materials}

Animals: Adult male Wistar rats (200 - $250 \mathrm{~g})(\mathrm{n}=30)$ were purchased from Animal house of faculty of Medicine, Assiut University. The animal room was maintained at $22^{\circ} \mathrm{C}-24^{\circ} \mathrm{C}$ and a lighting regimen of 12 hour light/ 12 hour dark. Rats were fed with standard house chow and water ad libitum. All animal experiments were performed after getting prior approval from the Institutional Animal Ethics Committee Assiut University.

Drugs: Ketamine (1867-66-9) and Dexamethasone (50-02-2) were purchased from Sigma-Tec Pharmaceutical Industries Egypt-S.A.E.

\subsection{Experimental Design}

Rats were divided into five groups ( $\mathrm{n}=6$ per group). Group I kept as control and received no treatment. Group II, III, IV, V were subjected to the induction of ulcerative colitis by intracolonic injection of $2 \mathrm{ml}$ acetic acid (4\% $\mathrm{v} / \mathrm{v}$ ). Thirty min before induction of colitis, group II was given normal saline (i.p.); group III was treated with dexamethasone (1 mg/kg, i.p.); Group IV, V were treated with ketamine (10 and $50 \mathrm{mg} / \mathrm{kg}$, i.p.) respectively.

\subsubsection{Induction of Colonic Inflammation}

All animals (except group I) were fasted for 6h prior to study, with access to water ad libitum and anesthetized by an intraperitoneal injection of $1 \%$ sodium pentobarbital in a dose of $50 \mathrm{mg} / \mathrm{kg}$ before induction of colitis, 2 $\mathrm{ml}$ acetic acid $(4 \% \mathrm{v} / \mathrm{v})$ in $0.9 \%$ saline were infused for 30s using a soft pediatric catheter size of $6 \mathrm{~F} 2 \mathrm{~mm}$ in diameter, inserted through rectum into the colon up to a distance of $8 \mathrm{~cm}$ and maintained in a supine Trendelenburg position for $30 \mathrm{~s}$ to prevent leakage of the intracolonic instill. On the $4^{\text {th }}$ day after operation, colon were collected after sacrificing the animals, portions of colon specimens were dissected out, washed with physiological saline and kept in 10\% formalin for macroscopic and histological studies [3] [12].

\subsubsection{Assessments of Colitis}

Macroscopic scoring: For each animal, the distal $10 \mathrm{~cm}$ portions of the colon were removed cut longitudinally and cleaned with physiological saline to remove fecal residues. Macroscopic inflammation scores are assigned based on the clinical features of the colon using a scale ranging from 0 - 4 as follows: 1 , intact epithelium with no damage; 2, patch type superficial hyperemia; 3, generalized patch type hyperemic regions; 4, generalized hyperemia and hemorrhage [13].

Histological analysis: The colon specimens $(2 \mathrm{~cm})$ collected from the animals were fixed in $10 \%$ formalin, embedded in paraffin and cut into $4 \mu \mathrm{m}$ sections. The paraffin sections were deparafinized with xylene, hydrated and stained with hematoxylin and eosin for studying mucosal damage assessment. The assessment was done as previously described by Noronha et al., [14] according to following scale: 0 , intact epithelium, no leukocyte or hemorrhage; 1, <25\% disrupted epithelium, focal leukocyte infiltrates and focal hemorrhage; 2, 25\% disrupted 
epithelium, focal leukocyte infiltrates and focal hemorrhage; 3, 50\% disrupted epithelium, widespread leukocytes, and hemorrhage; 4, >50\% disrupted epithelium, extensive leukocyte infiltration and hemorrhage.

Biochemical measurements: The colon tissue were homogenized in $10 \mathrm{mmol}$ Tris- $\mathrm{HCl}$ buffer (pH 7.4) and the homogenate were used for the measurement of Nitric oxide (NO), lipid peroxidation (LPO), reduced glutathione (GSH) and TNF- $\alpha$.

Malondialdehyde measurement: Lipid peroxidation, a major indicator of oxidative stress, was determined by measuring MDA level in tissue homogenate. MDA is a byproduct of the arachidonate cycle, its level was determined spectrophotometrically by using the thiobarbituric acid reactive substances method previously described by Ohkawa et al., (1979) [15]. A standard curve was run simultaneously with each set of samples by using 1, 1, 3, 3-tetramethoxypropane as an external standard. The results are expressed as nmol/gm wet tissue weight.

NO measurement: Nitric oxide formation was measured in tissue samples by assaying nitrite, one of the stable end products of NO oxidation, serum nitrite concentration was assayed spectrophotometrically by using Griess reaction according to the standard method described by Green et al. (1982) [16].

GSH measurements: The colon GSH content was determined using Ellman's reagent (5, 5-dithio-bis-2-nitrobenzoic acid) according to the method of Griffith (1980) [17]. A standard curve was prepared for each assay. The results are expressed as $\mu \mathrm{mol} / \mathrm{gm}$ wet tissue weight.

Determination of TNF- $\alpha$ : The colon tissue was used for measurement of TNF- $\alpha$ level according to the manufacturer's instructions using an immuno assay kit (Assaypro, LTA, Italy).

\subsection{Statistical Analysis}

Results are expressed as mean \pm SD. The data was analyzed by one way ANOVA followed by Dennett's test with post-hoc was employed. A p value $<0.05$ was considered significant.

\section{Results}

\subsection{Effect of Ketamine on Macroscopic Features}

Colonic instillation of acetic acid triggered an intense inflammatory response on the $4^{\text {th }}$ day of colitis induction, the distal colon showed severe macroscopic edematous inflammation. The mucosa was inflamed, ulcerated, hyperemic and hemorrhagic compared to normal control group. However, intracolonic treatment with dexamethasone and ketamine $(50 \mathrm{mg} / \mathrm{k}) 30 \mathrm{~min}$ before induction of ulcerative colitis attenuated the macroscopic damage and improved macroscopic scores. Ketamine $(50 \mathrm{mg} / \mathrm{kg}$ ) was found to be satisfactory in the protection of the rat colon against acetic-acid induced injury. No significant differences were seen between ketamine $(50 \mathrm{mg} / \mathrm{kg})$ and dexamethasone. However, low dose of ketamine $(10 \mathrm{mg} / \mathrm{kg}$ ) failed to improve macroscopic scores (Table 1).

\subsection{Effect of Ketamine on Histopathological Features}

Colonic mucosa of rats in the control group had a normal architecture with intact epithelium, signs of inflammation or necrosis were not observed (Figure 1(A)). Four days subsequent to the induction of colitis, the microscopic inspection of the colon revealed multifocal areas of necrosis, hemorrhage, submucosal edema, extensive polymorphonuclear granulocyte infiltration in the mucosa, the inflammation extended through the muscularis mucosae and submucosa, distorted crypts as well as massive necrotic destruction of the epithelium was observed

Table 1. Protective effects of ketamine $(10,50 \mathrm{mg} / \mathrm{kg}$, ip) on macroscopic and histologic features of the colon 4 days after induction of colitis.

\begin{tabular}{cccc}
\hline No. & Group & Macroscopic damage score & Histologic score \\
\hline I & Control & $1 \pm 0.00^{\mathrm{c}}$ & $0.00^{\mathrm{c}}$ \\
II & Acetic acid control & $4 \pm 0.1^{\mathrm{b}}$ & $3.9 \pm 0.3^{\mathrm{b}}$ \\
III & Dexamethasone (1 mg/kg, ip) & $1.3 \pm 0.9^{\mathrm{c}}$ & $1.4 \pm 0.3^{\mathrm{c}}$ \\
IV & Ketamine (10 mg/kg, ip) & $2.95 \pm 0.4$ & $2.8 \pm 0.2$ \\
V & Ketamine (50 mg/kg, ip) & $1.78 \pm 0.6^{\mathrm{c}}$ & $1.6 \pm 0.4^{\mathrm{c}}$ \\
\hline
\end{tabular}

Values are expressed as mean $\pm \mathrm{SD} ; \mathrm{n}=6$; ${ }^{\mathrm{b}} \mathrm{p}<0.05$ in comparison to control group; ${ }^{\mathrm{c}} \mathrm{p}<0.05$ in comparison to acetic acid control group. 

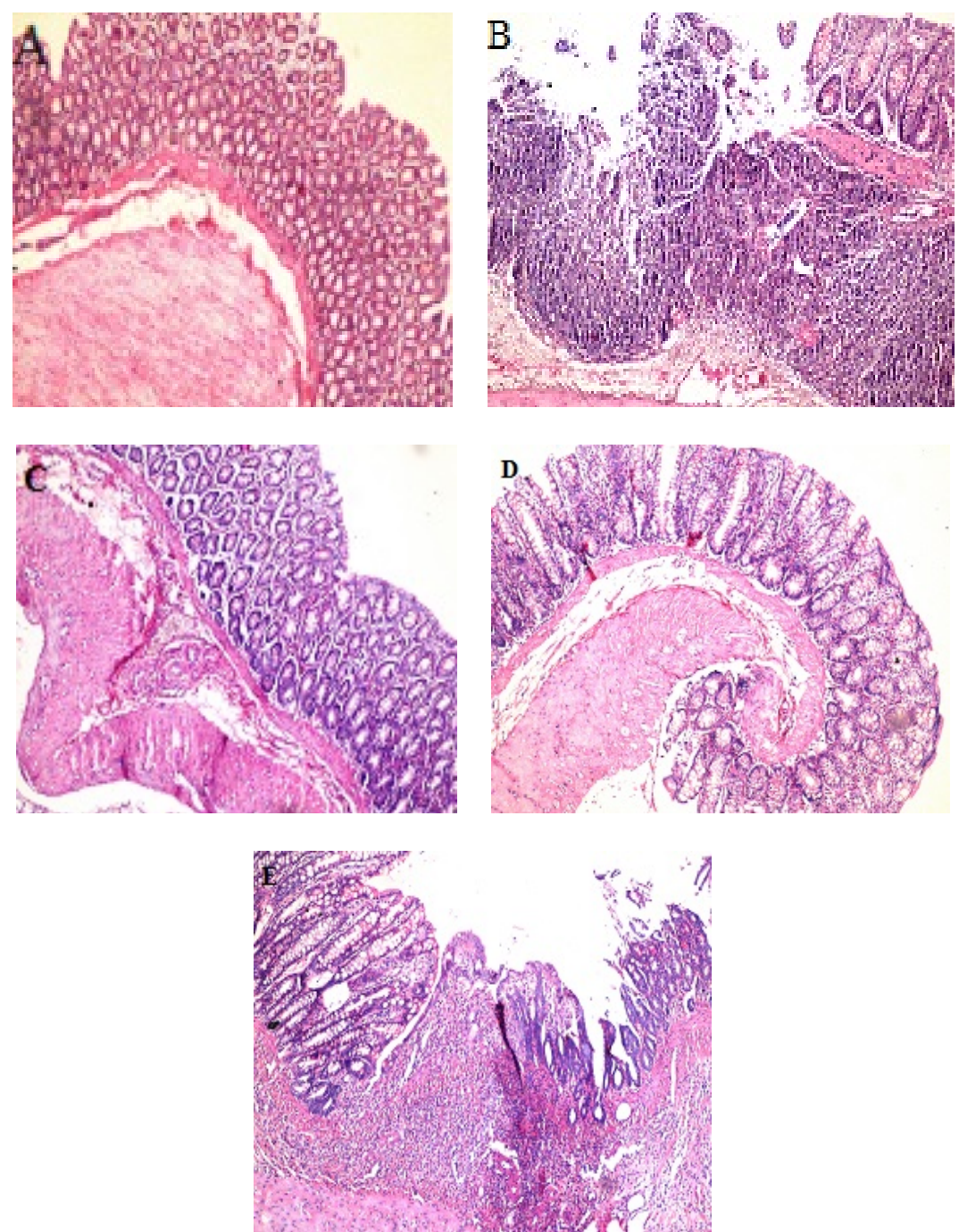

Figure 1. Effect of ketamine on colon histology. (A) Specimen from a normal rat showing colon with normal mucosa; (B) Control specimen from acetic acid induced rats showing colitis with large necrotic destruction of epithelial cells, areas of hemorrhage, submucosal edema and inflammatory cellular infiltration; (C) Colitis + Dexamethasone (1 mg/kg B. wt); (D) Colitis + Ketamine (50 mg/kg B. wt) + (E) Colitis + Ketamine (10 mg/kg B. wt) (100× magnification).

(Figure 1(B)). In ketamine (50 mg/kg) and dexamethasone treated groups, the histopathological changes were significantly attenuated, as judged by epithelization of the mucosa, reduction of edema and inflammatory cells recruitment (Figure 1(C), Figure (D)). No significant difference was observed between ketamine (50 mg/kg) and dexamethasone treated groups, both of them showed a significant decrease in the pathological scores in acetic acid-induced colitis rats as compared with the colitis control group. However, low dose of ketamine (10 $\mathrm{mg} / \mathrm{kg}$ ) showed focal disruption of epithelium and focal inflammatory cells in the lamina propria of all rats in this group (Figure 1(E), Table 1).

\subsection{Effect of Ketamine on Malondialdehyde Level}

Effect of ketamine on malondialdehyde level is shown in Figure 2. Administration of ketamine $(50 \mathrm{mg} / \mathrm{kg})$ or dexamethasone to acetic acid treated rats significantly reduced lipid peroxidation $(\mathrm{p}<0.05)$ compared to colitis group. However, ketamine $(10 \mathrm{mg} / \mathrm{kg})$ didn't show any significant differences in comparison to the colitis group. 


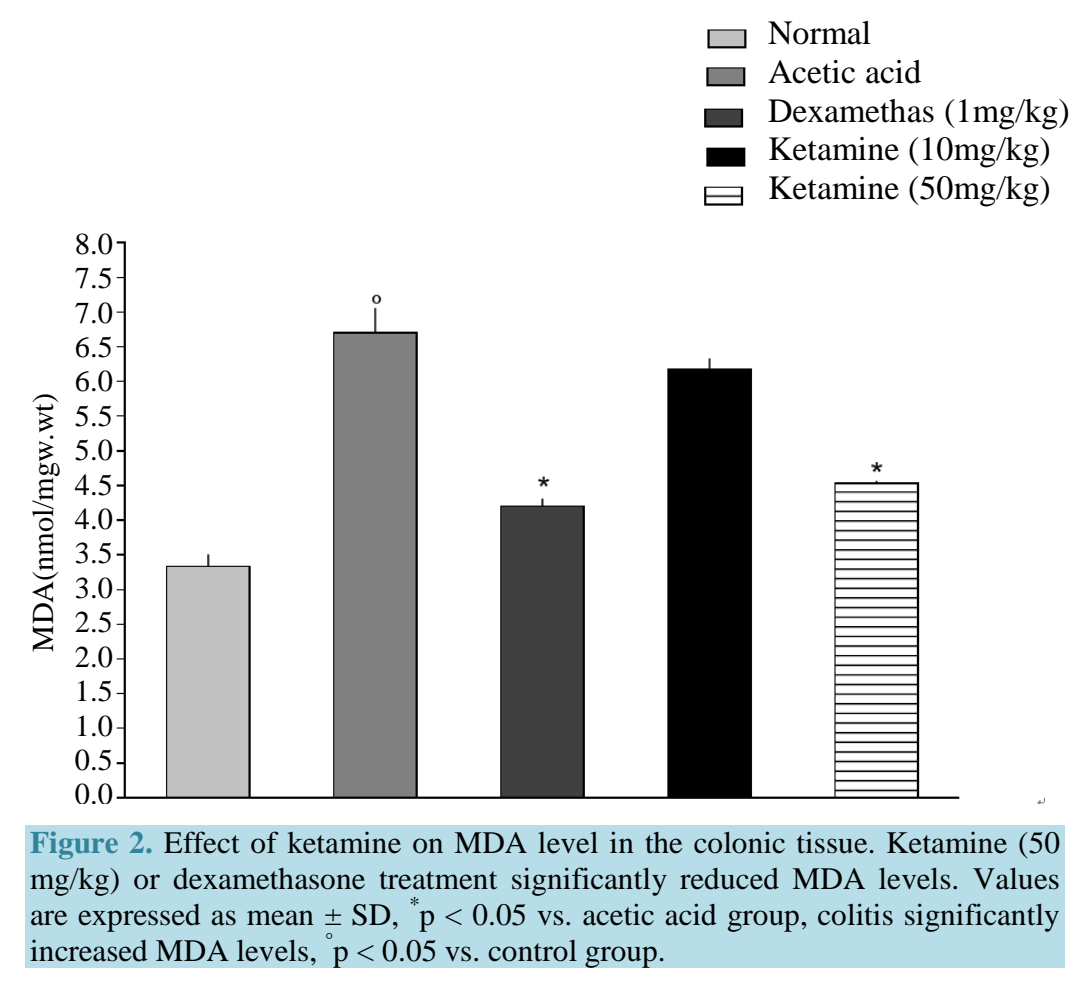

\subsection{Effect of Ketamine on Nitrite Level}

Nitrite was markedly enhanced in the inflamed colon after intrarectal acetic acid instillation. Treatment with either ketamine $(50 \mathrm{mg} / \mathrm{kg})$ or dexamethasone significantly $(\mathrm{p}<0.05)$ inhibited acetic acid induced NO production in tissue (Figure 3).

\subsection{Effect of Ketamine on GSH Level}

Effect of ketamine on colon GSH level is shown in Figure 4. The decreased colonic GSH in the colitis group was found to be significantly $(\mathrm{p}<0.05)$ increased after ketamine $(50 \mathrm{mg} / \mathrm{kg})$ and dexamethasone treatment.

\subsection{Effect of Ketamine on TNF- $\alpha$}

Colonic levels of TNF- $\alpha$ show drastic rise after acetic acid introduction compared with those of control group. In contrast these values were significantly lower in rats treated with ketamine $(50 \mathrm{mg} / \mathrm{kg})$ or dexamethasone. There were no significant differences in TNF- $\alpha$ levels between ketamine $(50 \mathrm{mg} / \mathrm{kg}$ ) and dexamethasone treated animals (Figure 5).

\section{Discussion}

Our study was focused on studying the effects of ketamine on acetic acid-induced colitis and our results clearly show that ketamine could inhibit experimental colitis. Ketamine administered 30 min before intracolonic instillation of $4 \%$ acetic acid caused a dramatic reduction in the severity of colitis which was comparable to dexamethasone. This effect is possibly attributed to its anti-inflammatory and antioxidant properties as indicated by improved macroscopic and histological features, correction of the increased biochemical markers MDA, nitrite, GSH and a decrease in colonic content of TNF- $\alpha$.

Ketamine is a noncompetitive N-methyl-D-aspartate (NMDA) receptor antagonist, extensively used as a safe and adequate intravenous or intramuscular anesthetic in various clinical situations. Ketamine is recommended for use in cases with a high risk of septicemia. It was reported that in addition to its anesthetic activity, it has novel anti-inflammatory properties [18]. However, no clear definitive mechanism for the anti-inflammatory action of ketamine has been suggested. 


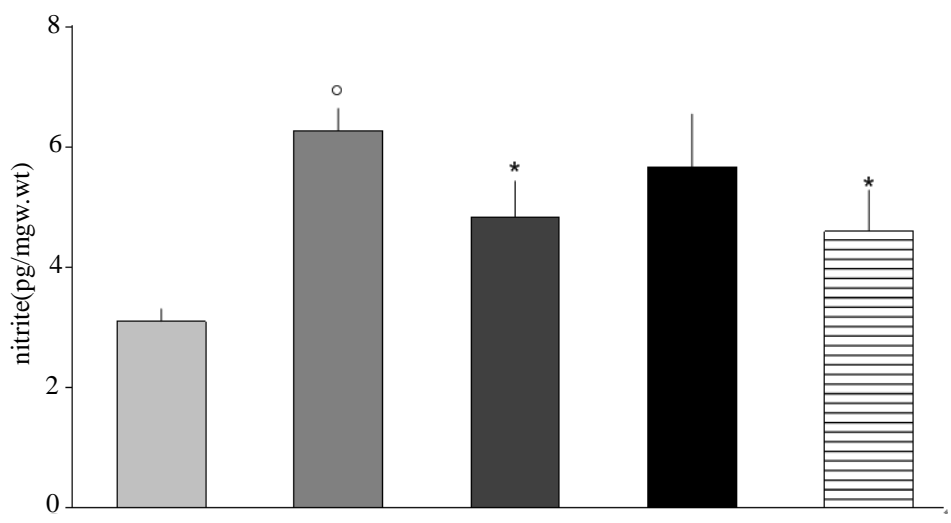

Figure 3. Effect of ketamine on NO level in the colonic tissue. Ketamine $(50 \mathrm{mg} / \mathrm{kg})$ or dexamethasone treatment significantly reduced NO levels. Values are expressed as mean $\pm \mathrm{SD},{ }^{*} \mathrm{p}<0.05$ vs. colitis group. Colitis significantly increased NO levels, $\mathrm{p}<0.05$ vs. control group.

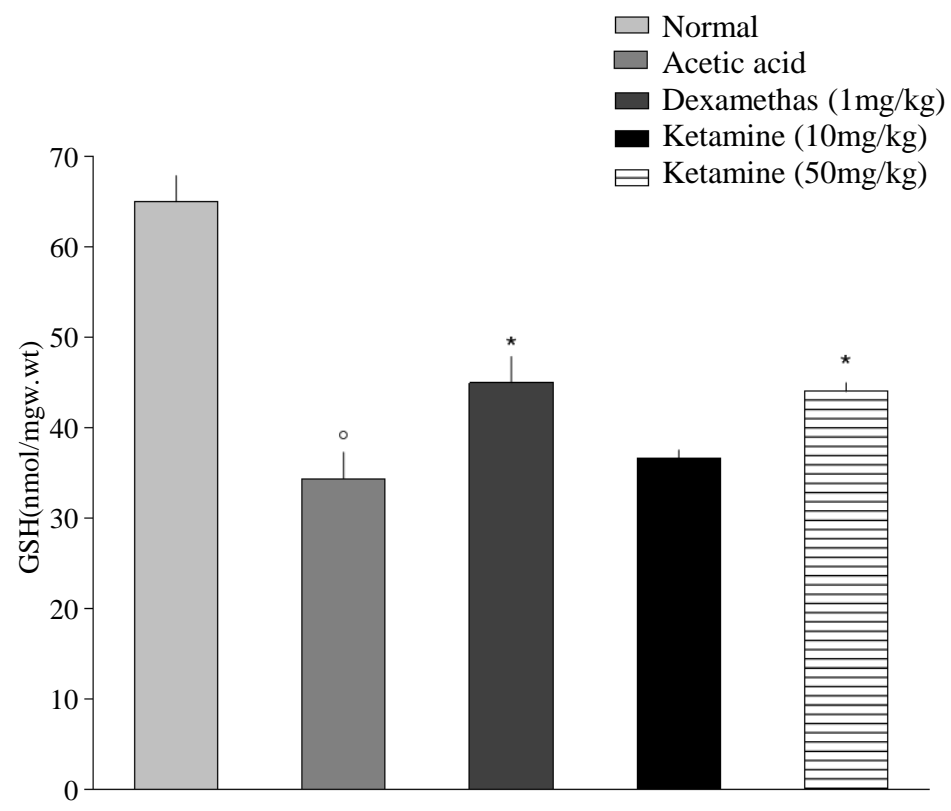

Figure 4. Effect of ketamine on GSH level in the colonic tissue ketamine $(50 \mathrm{mg} / \mathrm{kg})$ or dexamethasone treatment significantly elevated GSH levels. Values are expressed as mean $\pm \mathrm{SD},{ }^{*} \mathrm{p}<0.05$ vs. colitis group. Colitis significantly reduced GSH levels, $\mathrm{p}<0.05$ vs. control group.

It was reported that ROS (reactive oxygen species) generated in the inflamed mucosa can modulate many inflammatory events.ROS produce several inflammatory cytokines in various tissues which aggravate tissue damage. The free radicals produced during oxidative damage attack polyunsaturated fatty acids in plasma membrane leading to membrane lipid peroxidation and severe cell damage. This process plays a significant role in the pathogenesis of the disease [19]. In this study colitis control animals exhibited increased levels of MDA in colon 

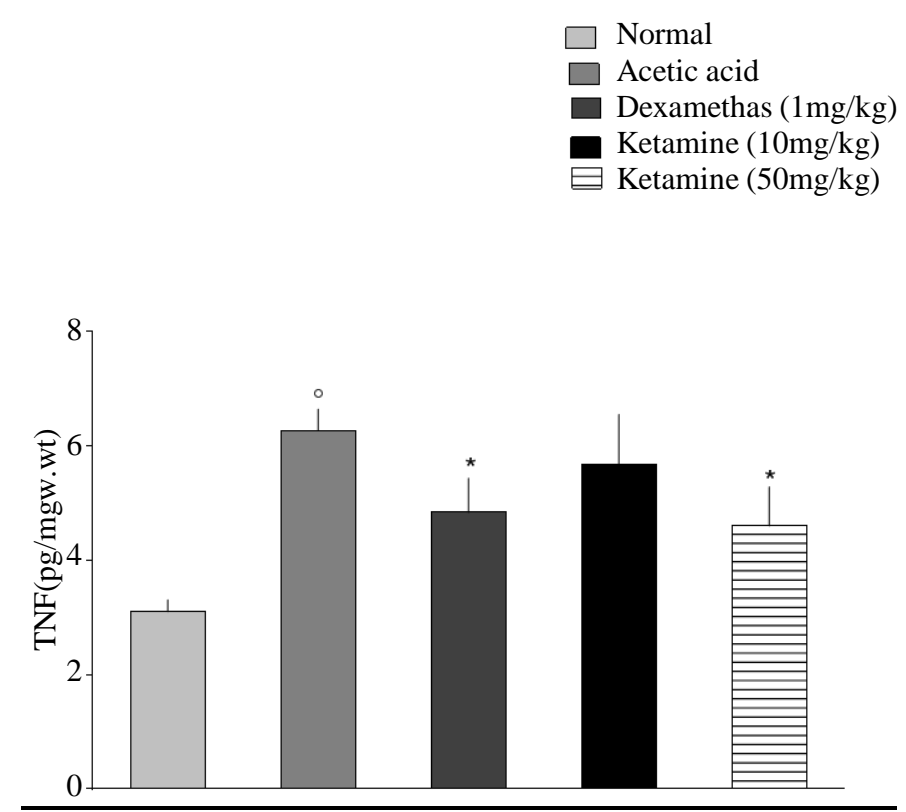

Figure 5. Effect of ketamine on TNF- $\alpha$ level in the colonic tissue. Ketamine $(50 \mathrm{mg} / \mathrm{kg})$ or dexamethasone treatment significantly reduced TNF- $\alpha$ levels. Values are expressed as mean \pm SD, ${ }^{*} \mathrm{p}<0.05$ vs. colitis group. Colitis significantly increased TNF- $\alpha$ levels, $\mathrm{p}<0.05$ vs. control group.

tissue. Ketamine treatment dramatically reduced the increased MDA levels. A significant reduction in MDA by treatment with ketamine exhibits the anti-inflammatory effect in the experimental colitis model and this may be related to the antioxidant and free radical scavenging ability of ketamine.

GSH is an important intracellular antioxidant agent in mammalian gut. It is involved in the repair mechanism as it inhibits mucosal damage by free radicals. During inflammation, GSH level decreases resulting in severe degradation of colon mucosa. Therefore GSH plays an important role in protecting the intestinal cells and as a defense mechanism against inflammation [20]. Treatment with ketamine significantly increased the colonic GSH level, reasonably, the mitigation of macroscopic and histopathologic indices.

NO is an important proinflammatory mediator. The nitric oxide and iNOS has been reported as potential mediators for colitis. During colitis, the observed inflammatory reactions as enhanced interstitial edema, increased arteriolar blood flow, fluid exudation across intestinal capillaries, thickening of the intestinal wall, are all associated with inflammatory mediators such as NO [21]. The present study showed that administration of ketamine significantly inhibited NO production which prevented peroxynitrite formation from inflammatory cells and countered inflammation.

The relationship between NMDA receptors and peripheral inflammatory responses has not been completely understood. Érces et al. 2012 [22], have proposed that $\mathrm{Ca}^{2+}$ over influx via the receptor associated ion channel activates excessive NO generation by NOS isoforms which mediate the downstream signal transduction of the NMDA receptors with subsequent excitotoxic neuronal cell death and intestinal malfunction. They postulated that reduction of the excessive NO generation by direct or indirect inhibition of NOS may be an appropriate approach for the treatment of intestinal inflammatory changes.

Ulcerative colitis has been associated with an intense local immune response which is associated with recruitment of lymphocytes and macrophages followed by release of soluble cytokines. Cytokines are crucial elements in gastrointestinal inflammation, however, their overproduction result injurious events.TNF is an important proinflammatory cytokine released from the macrophages and lymphocytes in the early inflammatory response. It has been reported to play an integral role in the pathogenesis of inflammatory bowel disease [23]. Blocking of TNF has been shown to inhibit colitis in animal models. It was increased following acetic acid instillation in our experiment. Ketamine treatment inhibits TNF production which may be due to inhibition of its synthesis or release. Our results parallel recent investigations showing anti-inflammatory properties of ketamine [24]. 
The anti-inflammatory effect of ketamine subanesthetic doses has been demonstrated in various animal models. It was found that ketamine produced a dose-dependent decrease in mortality with a significant reduction in the production of tumour necrosis factor- $\alpha$ (TNF- $\alpha$ ) and IL-6 after stimulation of lipopolysaccharide in carrageenan-sensitized mice injected with endotoxin [25]. Recent studies have demonstrated that ketamine inhibited the leucocyte production and release of various cytokines as TNF- $\alpha$, IL-6, IL-8 and nitric oxide and inhibited oxygen radical generation of isolated human neutrophils [18] [26] [27].

Guzman et al., 2010 [28], found that ketamine protection against intestinal I/R injury was related to a reduction of leukocytes, and particularly the infiltration of neutrophils. They reported that Ketamine pretreatment lowered inflammatory cell infiltration, sP-selectin serum levels, and reduced ATIII depletion. Moreover, Zahler et al., 1999 [29] have reported that ketamine alters neutrophil function and endothelial-neutrophil interactions, and some of its anti-inflammatory properties are related to its inhibitory effect on leukocyte reactivity [29] [30].

In 2005, Mazar et al., [18] have proposed the protective anti-inflammatory effects of ketamine are mediated by adenosine. They reported that ketamine administration causes release of adenosine in the periphery, and adenosine through A2A receptors, reduces the systemic inflammatory response by inhibition of secretion of proinflammatory cytokines as well as leukocyte activation and recruitment.

In clinical settings, the anti-inflammatory effect of ketamine has also been found. A low dose of ketamine $(0.25 \mathrm{mg} / \mathrm{kg})$ in patients undergoing coronary artery bypass surgery (CABG) has significantly suppressed intraoperative and postoperative increases in serum IL-6, IL-9 and C-reactive protein [31] [32]. This dose also significantly decreased superoxide production after on-pump coronary artery bypass graft surgery (CABG) [33].

The involvement of NMDA receptors in IBD has received little attention. Erces et al., 2012 [22] have reported that, NMDA antagonist treatment resulted in significantly reduced TNF- $\alpha$ and IL-6 levels 6 day after trinitrobenzesulfonic acid (TNBS) administration. Moreover, it was found that treatment with the endogenous NMDA receptor antagonist Kynurenic acid in the early phase of acute experimental colitis in rats reduced significantly plasma levels of (TNF- $\alpha$ ), inflammatory enzyme activities xanthine oxidoreductase (XOR), myeloperoxidase (MPO) and nitric oxide synthase (NOS), and colonic motility. They proposed that inhibition of the enteric NMDA receptors may provide a novel therapeutic option via which to influence intestinal hypermotility and inflammatory processes [34] [35].

\section{Conclusion}

We can conclude that, ketamine may be a new and effective therapy target in IBD patients. Further human studies would be beneficial elucidating the effect of ketamine more clearly and the possible therapeutic efficacy of ketamine in the treatment of UC, as well as the precise molecular basis of the protection it exerts over the intestinal mucosa.

\section{References}

[1] Nagib, M.M., Tadros, M.G., Elsayed, M.I. and Khalifa, A.E. (2013) Anti-Inflammatory and Antioxidant Activities of Olmesartan Midoxomil Ameliorates Experimental Colitis in Rats. Toxicology and Applied Pharmacology, 271, 106113. http://dx.doi.org/10.1016/j.taap.2013.04.026

[2] Sotnikova, R., Nosalova, V. and Navarova, J. (2013) Efficacy of Quercetin Derivatives in Prevention of Ulcerative Colitis in Rats. Interdisciplinary Toxicology, 6, 9-12. http://dx.doi.org/10.2478/intox-2013-0002

[3] MacPherson, B.R. and Pfeiffer, C.J. (1978) Experimental Production of Diffuse Colitis in Rats. Digestion, 17, 135-150. http://dx.doi.org/10.1159/000198104

[4] Noa, M., Mas, R., Carbaja, D. and Valdes, S. (2000) Effect of D-002 on Acetic Acid-Induced Colitis in Rats at Single and Repeated Doses. Pharmacological Research, 41, 391-395. http://dx.doi.org/10.1006/phrs.1999.0596

[5] Nosal'ova, V., Zeman, M., Černa, S., Navarova, J. and Zakalova, M. (2007) Protective Effect of Melatonin in Acetic Acid Induced Colitis in Rats. Journal of Pineal Research, 42, 364-370. http://dx.doi.org/10.1111/j.1600-079X.2007.00428.x

[6] Keshavarzian, A., Haydek, J., Zabihi, R., Doria, M., D’Astice, M. and Sorensen, J.R.J. (1992) Agents Capable of Eliminating Reactive Oxygen Species: Catalase, WR-2721, Cu(II) $)_{2}(3,5-\mathrm{DIPS})_{4}$ Decrease Experimental Colitis. Digestive Diseases and Sciences, 37, 1866-1873.

[7] Baumaqart, D.C. and Sandbom, W.J. (2007) Inflammatory Bowel Disease: Clinical Aspects and Established and Evolving Therapies. Lancet, 369, 1641-1657. http://dx.doi.org/10.1016/S0140-6736(07)60751-X 
[8] Takenaka, I., Ogata, M., Koga, K., Matsumoto, T. and Shigematsu, A. (1994) Ketamine Suppresses Endotoxin-Induced Tumor Necrosis Factor Alpha Production in Mice. Anesthesiology, 80, 402-408. http://dx.doi.org/10.1097/00000542-199402000-00020

[9] Taniguchi, T., Shbata, K. and Yamamoto, K. (2001) Ketamine Inhibits Endotoxin-Induced Shock in Rats. Anesthesiology, 95, 928-932. http://dx.doi.org/10.1097/00000542-200110000-00022

[10] Kawasaki, T., Ogata, M., Kawasaki, C., Ogata, J., Inoue, Y. and Shgemastu, A. (1999) Ketamine Suppresses Proinflammatory Cytokine Production in Human Whole Blood in Vitro. Anesthesia \& Analgesia, 89, 665-669.

[11] Kawasaki, C., Kawasaki, T., Ogata, M., Nandate, K. and Shgemastu, A. (2001) Ketamine Isomers Suppress Superantigen-Induced Proinflammatory Cytokine Production in Human Whole Blood. Canadian Journal of Anesthesia, 48, 819-823. http://dx.doi.org/10.1007/BF03016701

[12] Fabia, R., Willén, R., Ar’Rajab, A., Andersson, R., Ahrén, B. and Bengmark, S. (1992) Acetic Acid-Induced Colitis in the Rat: A Reproducible Experimental Model for Acute Ulcerative Colitis. European Surgical Research, 24, 211-225. http://dx.doi.org/10.1159/000129209

[13] Kuralay, F., Yildiz, C., Ozutemiz, O., Islekel, H., Caliskan, S., Bingol, B. and Ozkal, S. (2003) Effects of Trimetazidine on Acetic Acid-Induced Colitis in Female Swiss Rats. Journal of Toxicology and Environmental Health, 66, 169179. http://dx.doi.org/10.1080/15287390306402

[14] Noronha-Blob, L., Lowe, V.C., Muhlahauser, R.O. and Bruch, R.M. (1993) NPC 15669, an Inhibitor of Neutrophil Recruitment Is Efficacious in Acetic Acid-Induced Colitis in Rats. Gastroenterology, 104, 1021-1029.

[15] Ohkawa, H., Ohishi, N. and Yagi, K. (1979) Assay for Lipid Peroxides in Animal Tissues by Thiobarbituric Acid Reaction. Analytical Biochemistry, 95, 351-358. http://dx.doi.org/10.1016/0003-2697(79)90738-3

[16] Green, L.C., Wagner, D.A., Glogowski, J., Skipper, P.L., Wishnok, J.S. and Tannenbaum, S.R. (1982) Analysis of Nitrate, Nitrite, and $\left[{ }^{15} \mathrm{~N}\right]$ Nitrate in Biological Fluids. Analytical Biochemistry, 126, 131-138.

[17] Grififith, O.W. (1980) Determination of Glutathione and Glutathione Disulfide Using Glutathione Reductase and 2Vinylpyridine. Analytical Biochemistry, 106, 207-212. http://dx.doi.org/10.1016/0003-2697(80)90139-6

[18] Mazar, J., Rogachev, B., Shaked, G., Ziv, N.Y., Czeiger, D., Chaimovitz, C., Zlotnik, M., Mukmenev, I., Byk, G. and Douvdevani, A. (2005) Involvement of Adenosine in the Anti-Inflammatory Action of Ketamine. Anesthesiology, 102, 1174-1181. http://dx.doi.org/10.1097/00000542-200506000-00017

[19] Jena, G., Trivedi, P.P. and Sandala, B. (2012) Oxidative Stress in Ulcerative Colitis: An Old Concept but a New Concern. Free Radical Research, 46, 1339-1345. http://dx.doi.org/10.3109/10715762.2012.717692

[20] Chavan, S., Sava, L., Saxena, V., Pillai, S., Sontakke, A. and Ingole, D. (2005) Reduced Glutathione: Importance of Specimen Collection. Indian Journal of Clinical Biochemistry, 20, 150-152. http://dx.doi.org/10.1007/BF02893062

[21] Gillberg, L., Varsanyi, M., Sjostrom, M., Lordal, M., Lindholm, J. and Hellstrom, P.M. (2012) Nitric Oxide PathwayRelated Gene Alterations in Inflammatory Bowel Disease. Scandinavian Journal of Gastroenterology, 47, 1283-1297. http://dx.doi.org/10.3109/00365521.2012.706830

[22] Érces, D., Varga, G., Fazekas, B., Kovacs, T., Tökés, T., Tiszlavicz, L., Fülöp, F., Vécsei, L., Boros, M. and Kaszaki, J. (2012) N-Methyl-D-Asparate Receptor Antagonist Therapy Suppresses Colon Motility and Inflammatory Activation Six Days after the Onset of Experimental Colitis in Rats. European Journal of Pharmacology, 692, 225-234. http://dx.doi.org/10.1016/j.ejphar.2012.06.044

[23] Popivanova, B.K., Kitamura, K., Wu, Y., Kondo, T., Kagaya, T., Kaneko, S., et al. (2008) Blocking TNF-Alpha in Mice Reduces Colorectal Carcinogenesis Associated with Chronic Colitis. Journal of Clinical Investigation, 118, 560570.

[24] Gokcinar, D., Ergin, V., Cumaoglu, A., Menevse, A. and Aricioglu, A. (2013) Effects of Ketamine, Propofol, and Ketofol on Proinflammatory Cytokines and Markers of Oxidative Stress in a Rat Model of Endotoxemia-Induced Acute Lung Injury. Acta Biochimica Polonica, 60, 451-456.

[25] Koga, K., Ogata, M., Takenaka, I., Matsumoto, T. and Shigematsu, A. (1994) Ketamine Suppresses Tumor Necrosis Factor-Alpha Activity and Mortality in Carrageenan Sensitized Endotoxin Shock Model. Cardiogenic Shock, 44, 160168.

[26] Shimaoka, M., Iida, T., Ohara, A., Taenaka, N., Mashimo, T., Honda, T. and Yoshiya, I. (1996) Ketamine Inhibits Nitric Oxide Production in Mouse-Activated Macrophage-Like Cells. British Journal of Anaesthesia, 77, $238-242$. http://dx.doi.org/10.1093/bja/77.2.238

[27] Yu, Y., Zhou, Z., Xu, J., Liu, Z. and Wang, Y. (2002) Ketamine Reduces NF- $\kappa$ B Activation and TNF- $\alpha$ Production in Rat Mononuclear Cells Induced by Lipopolysaccharide in Vitro. Annals of Clinical \& Laboratory Science, 32, 292298.

[28] Guzman-DeLaGarza, F.J., Camara-Lemarroy, C.R., Ballesteros-Elizondo, R.G., Alarcon-Galvan, G., Cordero-Perez, P. 
and Fernandez-Garza, N.E. (2010) Ketamine Reduces Intestinal Injury and Inflammatory Cell Infiltration after Ischemia/Reperfusion in Rats. Surgery Today, 40, 1055-1062.

[29] Zahler, S., Heindl, B. and Becker, B.F. (1999) Ketamine Does Not Inhibit Inflammatory Responses of Cultured Human Endothelial Cells but Reduces Chemotactic Activation of Neutrophils. Acta Anaesthesiologica Scandinavica, 3, 10111016.

[30] Buras, J.A. and Reenstra, W.R. (2007) Endothelial-Neutrophil Interactions during Ischemia and Reperfusion Injury: Basic Mechanisms of Hyperbaric Oxygen. Neurological Research, 29, 127-131. http://dx.doi.org/10.1179/016164107X174147

[31] Roytblat, L., Talmor, D., Rachinsky, M., et al. (1998) Ketamine Attenuates the Interleukin-6 Response after Cardiopulmonary Bypass. Survey of Anesthesiology, 87, 266-271.

[32] Bartoc, C., Frumento, R.J., Jalbout, M., Bennett-Guerrero, E., Du, E. and Nishanian, E. (2006) A Randomized, Double-Blind, Placebo-Controlled Study Assessing the Anti-Inflammatory Effects of Ketamine in Cardiac Surgical Patients. Journal of Cardiothoracic and Vascular Anesthesia, 20, 217-222. http://dx.doi.org/10.1053/j.jvca.2005.12.005

[33] Zilberstein, G., Levy, R., Rachinsky, M., et al. (2002) Ketamine Attenuates Neutrophil Activation after Cardiopulmonary Bypass. Anesthesia \& Analgesia, 95, 531-536.

[34] Varga, G., Érces, D., Fazekas, B., Fülöp, M., Kovacs, T., Kaszaki, J., Fülöp, F., Vécsei, L. and Boros, M. (2010) N-Methyl-D-Asparate Receptor Antagonism Decreases Motility and Inflammatory Activation in the Early Phase of Acute Experimental Colitis in the Rats. Neurogastroenterology \& Motility, 22, 217-225. http://dx.doi.org/10.1111/j.1365-2982.2009.01390.x

[35] Hirota, K. and Lambert, D.J. (2011) Ketamine: New Uses for an Old Drug. BJA, 107, 123-126. http://dx.doi.org/10.1093/bja/aer221 